\title{
Comments on the Article "Results of Simple Conservative Treatment of Midfoot Charcot Arthropathy": To the Editor
}

\author{
Nicolas Gallardo-Molina, MD \\ Research Department at Medical School, Espíritu Santo University (UEES), Samborondon, Ecuador
}

The article by Kim et al. ${ }^{1)}$ offers important and interesting information on the management of midfoot Charcot arthropathy. This manuscript presents satisfactory results of a conservative treatment without restriction of daily living activities. However, much of the literature manifests other types of treatment for this pathology. The aim of this letter is to provide a short review on the treatment of midfoot Charcot arthropathy with latest evidence.

Botek et al. ${ }^{2)}$ stated that offloading is the key to treatment because it gives the time to heal and arrest the progressive tissue damage and deformities. This should remain until the inflammation disappears (3 to 12 months, approximately). However, nowadays surgical correction of the Charcot deformity has good supporting evidence. The different techniques include exostectomies, muscle flaps, arthrodesis with internal or external fixation. The circular external fixation is considered to be biomechanically superior to the others. Indications for surgical intervention are unstable joints, nonhealing or infected ulcers, equinus deformities, and unbraceable deformities.

A case report by Higgins et al. ${ }^{3)}$ also presents a 58-year-old diabetic man with an acute Charcot arthropathy, in which offloading was essential for the treatment of the foot. The authors demonstrated that surgery is not useful in acute cases; however, the surgical procedures mentioned previously have demonstrated variable success in the treatment of deformities in chronic Charcot arthropathy. Therefore, the initial treatment of this patient was immobilization with total contact casting, which is the gold standard in acute cases.

The offloading therapy is critical in the initial treatment of Charcot arthropathy because it gives the chance of healing properly without weakening deformities and preserves longitudinal arch; however, there are cases that are not successful. For these cases, Rosskopf et al. ${ }^{4)}$ recommended stabilization with the Ilizarov external fixator (or ring fixator) frame as an alternative treatment option for offloading in patients with severe deformity or after removal of osteomyelitic bone fragments.

Raspovic et al. ${ }^{5)}$ stated that surgical reconstruction usually consists of a combination of tendon releases/ lengthening, fusions, and osteotomies as needed to address the deformity. The goal is to give stability so the patient can achieve free ambulation. One of the surgical techniques is to release the contracted soft tissue to correct deformity. This is done percutaneously or open via three small incisions. On the other hand, the intramedullary fixation of the medial and lateral columns for midfoot Charcot arthropathy reconstruction allows control of the transverse arch of the foot and to this a fusion of the subtalar joint can be added in order to limit frontal and transverse plane torsion and achieve greater stability. However, internal fixation is not recommended in cases of infection.

Charcot arthropathy is a severe complication of diabetes mellitus that mainly affects the patient's quality of life. Ambulation is severely limited, so the periodic control of this type of patients is an essential part of reporting early findings of arthropathy, and thus, avoiding invasive interventions that harm rather than benefit the evolution of the disease.

\section{CONFLICT OF INTEREST}

No potential conflict of interest relevant to this article was reported.

Received February 4, 2020; Accepted February 6, 2020

Correspondence to: Nicolas Gallardo-Molina, MD

Research Department at Medical School, Espíritu Santo University (UEES), Vía Samborondón km 2.5, Samborondon 092302, Ecuador

Tel: +593-991160513

E-mail: gallardonicolasm@gmail.com

Copyright (C) 2020 by The Korean Orthopaedic Association 
Letter to the Editor

Clinics in Orthopedic Surgery • Vol. 12, No. 2, $2020 \bullet$ www.ecios.org

\section{REFERENCES}

1. Kim YK, Lee HS, Seo SG, Park SH, Boedijono D. Results of simple conservative treatment of midfoot Charcot arthropathy. Clin Orthop Surg. 2019;11(4):459-65.

2. Botek G, Figas S, Narra S. Charcot neuroarthropathy advances: understanding pathogenesis and medical and surgical management. Clin Podiatr Med Surg. 2019;36(4):663-84.

3. Higgins A, Teixeira M, Szostek JH. 58-Year-old diabetic man with a warm, erythematous foot. Mayo Clin Proc. 2019;
94(3):526-30.

4. Rosskopf AB, Loupatatzis C, Pfirrmann CW, Boni T, Berli MC. The Charcot foot: a pictorial review. Insights Imaging. 2019;10(1):77.

5. Raspovic KM, Liu GT, Lalli T, Van Pelt M, Wukich DK. Optimizing results in diabetic Charcot reconstruction. Clin Podiatr Med Surg. 2019;36(3):469-81. 


\section{You Keun Kim, Ho Seong Lee, Sang Gyo Seo, Seung-Hwan Park, Dimas Boedijono, Reply:}

We thank Dr. Gallardo-Molina for your interest in our recent paper published in December 2019 issue of Clinics in Orthopedic Surgery. We appreciate the opportunity to share our thoughts on the points raised by Dr. GallardoMolina as below.

As you mentioned, Charcot arthropathy is a severe complication of long-standing diabetes mellitus (DM), which mainly affects the patient's quality of life. Ambulation can be severely limited by the foot deformity or the chronic illness itself. The goal of treatment of Charcot arthropathy is to achieve a stable, plantigrade foot. Therefore, the focus of treatment is on minimizing the impact of the diabetes-related, serious comorbidity rather than obtaining anatomical restoration of the midfoot. There is no debate on the importance of minimal restriction on daily living activities in the management of DM. Poor glucose control profoundly increases the incidence and severity of various chronic complications associated with $\mathrm{DM},{ }^{1)}$ and functional ambulation is mandatory for effective glucose control. We reported that sarcopenia increases the risk for mortality in patients who undergo amputation for a diabetic foot. ${ }^{2)}$ We believe that long-term immobilization after reconstructive surgery or inconvenience due to total contact casting (TCC) would adversely affect the patient's functional ability.

In the management of hindfoot Charcot arthropathy, hindfoot arthrodesis surgery or rigid cast immobilization is necessary to prevent its progression to hindfoot deformity or instability, which will eventually result in poor walking ability. However, in the case of midfoot Charcot arthropathy, limitation of walking ability is minimal even with some degrees of midfoot deformity. In our study, midfoot Charcot arthropathy showed little progression without TCC, arthrodesis, or reconstructive surgery. Meaningful arch collapse occurred only in four of 38 feet $(10 \%)$ and the patients could ambulate well even with a flattened foot. Among the 38 feet (34 patients), plantar ulcers related to bumps were found in two feet (5.3\%) and bump-related plantar pain occurred in three feet $(7.8 \%)$.
Simple bumpectomy may be needed for selective cases of plantar bump-related ulcer or pain.

For the treatment of Charcot arthropathy, offloading procedures are important, and TCC can be a good option. However, it has potential complications: ${ }^{3)}$ cast-related problems, such as muscle atrophy and poor hygiene, should be considered. Successful TCC, even in the hands of an experienced physician, may result in subsequent ulcerations in $30 \%$ of patients during treatment. ${ }^{3)}$ Furthermore, it is difficult to determine when and how long the TCC should be applied. It is not easy to assess the Eichenholtz stage. As you mentioned with the Botek's report, it takes approximately 3 to 12 months until acute inflammation disappears. ${ }^{4)}$ There is no well-designed comparative study about the effect of TCC on prevention of arch collapse in midfoot Charcot arthropathy.

Surgical reconstruction of midfoot Charcot arthropathy has technical difficulties and associated complications. ${ }^{5-8)}$ Although many surgical trials have been conducted for successful midfoot Charcot arthropathy, no gold standard surgery has been established. Invasive interventions can cause more harm than good. Considering complications related to TCC and reconstructive surgery, we suggested a simple treatment strategy that focuses on ulcer control rather than reconstruction for midfoot Charcot arthropathy. For some cases, however, simple bumpectomy with close follow-up may be needed to prevent catastrophic infections.

\section{CONFLICT OF INTEREST}

No potential conflict of interest relevant to this article was reported.

Correspondence to: Ho Seong Lee, MD

Department of Orthopedic Surgery, Asan Medical Center, 88 Olympic-ro 43-gil, Songpa-gu, Seoul 05505, Korea

Tel: +82-2-3010-3521, Fax: +82-2-488-7877

E-mail: hosng@amc.seoul.kr

https://doi.org/10.4055/cios20025re

\section{REFERENCES}

1. Han HS, Kang SB. Relations between long-term glycemic control and postoperative wound and infectious complications after total knee arthroplasty in type 2 diabetics. Clin Orthop Surg. 2013;5(2):118-23.

2. Kim YK, Lee HS, Ryu JJ, Lee HI, Seo SG. Sarcopenia in- creases the risk for mortality in patients who undergo amputation for diabetic foot. J Foot Ankle Res. 2018;11:32.

3. Guyton GP. An analysis of iatrogenic complications from the total contact cast. Foot Ankle Int. 2005;26(11):903-7.

4. Botek G, Figas S, Narra S. Charcot neuroarthropathy ad- 
Letter to the Editor

Clinics in Orthopedic Surgery • Vol. 12, No. 2, $2020 \bullet$ www.ecios.org

vances: understanding pathogenesis and medical and surgical management. Clin Podiatr Med Surg. 2019;36(4):66384.

5. El Oraby HA, Abdelsalam MM, Eid YM, El Hilaly R, Marzouk HA. Bone mineral density in type 2 diabetes patients with Charcot arthropathy. Curr Diabetes Rev. 2019;15(5): 395-401.

6. Papanas N, Maltezos E. Etiology, pathophysiology and classifications of the diabetic Charcot foot. Diabet Foot
Ankle. 2013 May 21 [E-pub]. https://doi.org/10.3402/dfa. v4i0.20872.

7. Sammarco VJ, Sammarco GJ, Walker EW Jr, Guiao RP. Midtarsal arthrodesis in the treatment of Charcot midfoot arthropathy. J Bone Joint Surg Am. 2009;91(1):80-91.

8. Assal M, Stern R. Realignment and extended fusion with use of a medial column screw for midfoot deformities secondary to diabetic neuropathy. J Bone Joint Surg Am. 2009;91(4):812-20. 